\title{
Adenoviral Cancer Vaccine PF-06936308
}

National Cancer Institute

\section{Source}

National Cancer Institute. Adenoviral Cancer Vaccine PF-06936308. NCI Thesaurus. Code C156015.

A cancer vaccine composed of a replication-defective E1-deleted adenovirus vector based on chimpanzee adenovirus serotype 68 (AdC68) expressing three not yet disclosed tumor-associated antigens (TAAs), with potential immunostimulating and antineoplastic activities. Upon vaccination with the adenoviral cancer vaccine PF-06936308, the adenovirus infects cells and expresses the TAAs. In turn, the TAAs activate the immune system to produce a cytotoxic T-lymphocyte $(\mathrm{CT} L)$ response against cells expressing the TAAs. 